\title{
Animating Management
}

How does one sculpt water? It is an absurd idea, like trying to nail Jell-O to the wall. Yet a considerable amount of contemporary computer animation entails making and sculpting such unruly and unpredictable things: snowstorms, clouds, fire, hair, cloth, water, and, in fact, Jell-O. Developing tools for this type of animation has been the subject of considerable effort by large studios and software companies for decades. One can essentially take each major animated feature from Hollywood studios like Walt Disney Animation and Pixar Animation from the past few decades and single out a key example of this type of animation being put on display in each film. Monster's Inc. (2001) and Brave (2012) prominently featured hair and cloth animation by iterations of Pixar's "FizT" software, Frozen (2013) features Disney's "Matterhorn" snow simulation software, and Moana (2016) features water animation powered by Disney's "Splash" fluid solver. These types of animation all require the creation of an unpredictable, chaotic type of motion that can be shaped by manipulating parameters without losing its uncanny naturalistic quality. The same techno-scientific concept of creating something unpredictable and shaping it, without losing its ineffable quality, is also at work in the way large contemporary animation studios represent their approach to management to the public. Public relations and promotional representations of studio workspaces and work cultures are full of examples of how they create conditions for unpredictable things to happen and occasion the unexpected as a part of the creative process.

(C) The Author(s) 2021

J. Gowanlock, Animating Unpredictable Effects, Palgrave Animation, https://doi.org/10.1007/978-3-030-74227-0_5 
Both these types of animation tools and these management concepts hinge on the idea of modeling and simulating nonlinear systems, using random number generators or dynamic interactions to simulate unpredictable behavior in systems. Since the military-industrial-academic complex of the Second World War, computer simulation has been used by a variety of disciplines to understand various unpredictable and dynamic phenomena like weather patterns or financial markets. A key application of this concept has been management science, which uses simulation to design resilient systems for an unpredictable world. While management science is part of a long tradition of industrial management theory, it represents a different era in the epistemology of management as compared with the scientific management practiced by the likes of Fredrick Winslow Taylor, which was influential to animation management in the early twentieth century, as work by scholars such as Donald Crafton have shown. ${ }^{1}$

The linkage between nonlinear animation and management can be observed across contemporary animation, visual effects, and interactive game production, but this chapter is limited to the case of Pixar. Pixar's founders were all computer graphics research pioneers who worked on some of the earliest applications of nonlinear simulation for computer animation. Pixar invests considerably more effort into promoting its management theory than its contemporaries. The studio trumpets its approach to management through popular books, business journal articles, DVD extras, and behind-the-scenes public relations campaigns. These materials shape Pixar's particular corporate ethos for its audiences, its employees, its software customers, and potential investors. As a Bay Area tech company that began to model itself as an animation studio, Pixar carefully sculpts its corporate identity as innovative yet in tune with animation history, and the concept of nonlinearity plays an important role in negotiating this hybrid identity.

As work by Nicholas Sammond finds, early industrial animation studios such as Bray Productions, Fleischer Studios, and Walt Disney Productions sought to emphasize the unpredictable liveliness of creativity at their studios while also demonstrating their ability to control and manage that unpredictability through Taylorist and Fordist industrial management techniques that promoted regulation and efficiency. ${ }^{2}$ Pixar similarly seeks to promote their creativity and industrial efficacy, at once maintaining a connection to studios like Disney while also dispensing with restrictive, routinized aspects of industrial management and promoting the neoliberal Silicon Valley entrepreneurial myths of their origins as well as their 
post-Fordist management techniques. Their nonlinear approach to animation negotiates this complexity and promotes a harmonious, uncomplicated, and fun vision of creative labor. Pixar represents creativity as the result of unpredictable interactions and random processes, and they promote the way this randomness and complexity can be cultivated and directed through the manipulation of conditions and parameters. Unpredictability can thus be integrated into the production process by managing the conditions that generate it. Pixar renders management as a form of animation, as a way of enlivening and occasioning the unexpected, and they render animation as a nonlinear simulation task.

In Siegfried Zielinski's words animation is an "interdiscursive phenomenon," with a diverse genealogy of different meanings grounded in the concept of introducing a life force to a material body. ${ }^{3}$ Through history this vital animating force has been many things, including a soul, a spirit, or electricity. In the case of Pixar this animating force is nonlinear contingency. This is what makes nonlinear animations like the splashing water in Finding Nemo (2003) look so uncannily lifelike, and it is also what the studio sees as a key animating component in how they produce their innovative films and technology.

Pixar's algorithmic way of thinking promises to resolve the tension found in early industrial studios between creativity and control. By treating management as a computational tool, by approaching management like they approach the simulation of splashing water, Pixar further promotes a vision of neutral technocratic management that elides issues of labor justice and equity and promotes an image of the studio as a utopic harmonious space that fosters creativity. This is a vision of control that grew from a nexus between animation, technology, and management theory, and it utilizes a similar logic observed by scholars such as Tarleton Gillespie, Cathy O'Neil, and Safiya Noble where algorithms and software platforms are constructed as objective and neutral in such a way as to obfuscate politics. ${ }^{4}$ Understanding this helps to explain how Pixar has dealt with labor issues, including recent cases of workplace harassment, but this research also provides insight into broader trends in creative management that Pixar has inspired.

Pixar is often made to represent the introduction of Silicon Valley neoliberalism (and related post-Fordist labor practices) to the American film industry. Former Pixar CFO Lawrence Levy styles the studio as "bringing Silicon Valley bravado to Hollywood." 5 Paul Flaig describes the studio as a "vanguard" of post-Fordism and as "representing a manifold turn from 
Hollywood's film factory to Silicon Valley." The post-Fordist approach to managing creative labor in this context is defined as the erasure of the line between private life and work life and by the autonomy (and precarity) of the self-managed contract worker or entrepreneur. ${ }^{7}$ While Pixar's management theory conforms closely to the former, it deviates in some interesting ways from the latter. As the following pages will explain, seen through the frame of nonlinearity, creativity is not a fugitive, ephemeral resource to be captured. Rather it is something that can be generated and directed through the manipulation of conditions and parameters. Thus creativity is something that is fostered in-house rather than being contracted out.

\section{SCIENTIFic Management and Early \\ INDUSTRIAL ANimATion}

When industrial management techniques were first introduced to the craft of animation in the 1910s they brought about certain points of tension; the rigid and routinized style of industrial management had to be reconciled with a discourse of chaotic, unpredictable creativity. On one hand animation studios promoted their ability to bring things to life, creating unpredictable situations and characters with a mind of their own, one the other hand, yet at the same time they accomplished this feat through a highly routinized, deterministic, and linear process. Scott Bukatman observes this dynamic in both animation and early American comics, and he attributes it to the historical context of turn-of-the-century America, where an ideology of opportunity and self-determination existed in tension with the highly regulated realities of industrial labor. ${ }^{8}$ This dynamic between creative chaos and management is still relevant in contemporary animation industries. What has changed is the conceptual framework used to understand it.

The industrialization of early animation coincided with the ascendance of scientific management, which approached the management of labor as an engineering task. ${ }^{9}$ With a focus on output and efficiency, scientific management employed empirical and technical analytical tools to understand labor tasks and improve worker efficacy and efficiency. Scientific management is associated with a few key figures from the early twentieth century such as Frank Bunker Gilbreth and Henri Gantt but the movement has become synonymous with one key figure, Fredrick Winslow Taylor, the author of the seminal 1911 book The Principles of Scientific Management. 
The idea of applying "science" to the management of labor is a somewhat vague concept, more indicative of the desire for epistemic authority and a declaration of alignment with a positivist zeitgeist rather than any specific set of methods or theories. Yet the title of "science" is more appropriate when one considers Taylor's key contribution to the history of management. While he invented a number of concepts and techniques, his fundamental contribution was the idea of examining the practice of management itself: to theorize the role of management and make it more than the mere oversight of workers. ${ }^{10}$ This was the study, or science, of management. While new approaches to management that focused on hierarchies, bureaucracy, and psychology would replace scientific management in a relatively short period of time, this reflexive disposition toward management would be Taylor's enduring legacy. Theorization of management would have an important influence on animation production over time, both in terms of how animation production processes were designed and in terms of how the process of animation was understood and represented.

Although the first forms of cinematic animation were largely the product of craftwork by individual artists like Winsor McCay or Émile Cohl, by 1913 cinematic animation started to take on elements of industrial production. During the following years studios like Bray Productions and Fleischer Studio began implementing techniques and technologies in the name of improved consistency, efficiency, and output. Examples include the use of celluloid, registration pegs, rotoscope, standard production references, and the emergence of specialized below-the-line labor roles like inkers and inbetweeners. ${ }^{11}$ Donald Crafton's research offers substantial evidence that John Randolph Bray in particular was engaging Taylor's ideas and applying them to animation. ${ }^{12}$ Animation studios were thus studying the animation process and reflecting on how it might be done differently with the implementation of different configurations of labor and technology.

Evidence of this management theorization can be seen both in the films produced by these studios and in promotional communications about the studios. In the case of promotional materials, Sammond's research on fan magazines and trade publications finds that studios like Fleischer's were eager to show off their "rationalized" and efficient industrial animation processes. This should not be taken to mean that they wanted to look mechanical and boring though. Sammond notes that while the earliest representations of the task of animation by Winsor McCay represented animation as an onerous grind, as studios became more industrialized they 
tended to represent the process of animation as being more "playful and capricious" while also being more efficient, "rational and productive." 13 The studios were interested in showing that their workers were lively and fun, but also that the studio producers and managers were able to "corral the rambunctious energy of its animators." 14 The promotional material portrayed this relationship not as one of animosity but of paternalistic guidance. Sammond further finds that the complexity of this relationship between unpredictable liveliness and managing direction is more obliquely evident in animations from this period, like the Fleischer Studio's Out of the InkWell series. Here the rebellious and mischievous animated character Koko the Clown is contained and managed by the live-action animator that drew him. ${ }^{15}$ Sammond finds that "animators created a commodity that appeared to speak back to its creators and assert its independence from the social and material order of its making ... only inevitably to be put in its place." 16

This transitional period of early industrialized animation eventually gave way to more settled and conventionalized portrayals of animation production, typified by Walt Disney Productions. Here the work of creating an animated film was no longer portrayed as the manual work of drawing, but as the industrial management task of directing an extensive studio with numerous departments of specialized workers. ${ }^{17}$ A promotional film that followed the release of Snow White and the Seven Dwarfs (1937) titled How Walt Disney Cartoons Are Made (1939) offers a good example of this. The film portrays Walt Disney overseeing the studio's many departments, directing the inking department, filled with "hundreds of pretty girls in a comfortable building all their own," as well as the story department, where writers and the studio's "hard boiled directors" develop ideas. The film is careful to note that although many people work on a given film, Disney always gives direction and final approval. The management of labor, particularly its division, thus affords creativity. The "pretty girls" are compartmentalized, rendering their labor as rote, menial, and linear. Having someone or something to do the repetitive work of animation exactly as directed allows animators and managers to do the creative work. Animation is rhetorically transformed into management by Disney: the people in charge are the creators, and the ones that do the work merely follow directions.

Like Walt Disney Productions, Bray Productions, and Fleischer Studios, Pixar has sought to convey its management theory through public relations and promotional material. Pixar's representations of management 
also seek to negotiate this dynamic between anarchic liveliness and control. However, these concepts are mediated through a very different epistemic frame. While early studios like Bray Productions and Fleischer Studios focused on management as routinized, efficient, and rigid, the following sections will show how Pixar focuses on embracing unpredictably, flexibility, and resilience. While Disney used the linear work done by departments of below-the-line workers to make above-the-line animators and executives seem livelier and more creative, Pixar instead promotes its use of nonlinear processes that purport to integrate input from all levels of staff in an egalitarian fashion and inspire the unpredictable chaos that studios like Fleischer and Disney sought to corral and rationalize. By couching their approach to management in the same concept of nonlinearity that drives many of their animation tools, Pixar furthers this collapse between animation as making moving images and animation as management, and it further obfuscates points of labor conflict in a black box of computational paradigms.

\section{Nonlinear Simulation at Pixar}

As Chap. 2 explained, modeling and simulating nonlinear systems requires some element of unpredictability. One way of doing this is simply to use a random number. By inserting some random factor into an otherwise predictable simulation you can see what types of outcomes are possible. This is referred to as a stochastic simulation. Another approach is to use dynamics. Here, if you set up multiple sets of rules that influence each other in turn (A influences B, which influences $\mathrm{C}$, which influences $\mathrm{A}$ ) the result is complex and unpredictable. The concept of nonlinear simulation has influenced a variety of research and engineering fields, including computer graphics and management science. This way of thinking has been fundamental to Pixar since before it was an independent company, and it continues to influence the way the company constructs itself.

The computer graphics scientists who founded Pixar, William T. Reeves, Loren Carpenter, Alvy Ray Smith, and Ed Catmull, are all well versed in the concept of nonlinear simulation. Indeed, three of the four founders made some of the most important early contributions to nonlinear animation technology. Many of the early technologies they developed are on display in their first Hollywood contract, the "genesis sequence" in Star Trek II: The Wrath of Khan (1982), which they completed while still under the aegis of Lucasfilm's computer division. The genesis sequence was led 
by Alvy Ray Smith, a computer science researcher who had been teaching at NYU. Smith did his doctoral research on cellular automata, the type of simulation where simple rules applied to a grid of squares lead to unpredictable patterns through dynamic interactions. The sequence also prominently features former Boeing researcher Loren Carpenter's fractal topographies, ${ }^{18}$ and former researcher at the University of Toronto William T. Reeves' particle systems, a way of rendering volumetric things like fire or smoke as individual points whose motion paths are generated algorithmically, creating nonlinear shapes and movement. ${ }^{19}$

The genesis sequence is the first of many examples of nonlinear animation that this group would produce. Following their separation from Lucasfilm, Pixar released a series of new nonlinear simulation techniques at the Association for Computing Machinery's special interest group on graphics (SIGGRAPH), with each new technical advance illustrated with an animated tech demo. For example, in 1986, Reeves worked with researcher Alain Fournier to develop a system for animating ocean waves and rippling fabric, a technique they showcased in a demo titled Flag and Waves. Pixar has consistently developed nonlinear simulation technology since. Many subsequent technologies came from long-time Pixar scientist Michael Kass. Over his career Kass helped develop an influential fluid simulation, ${ }^{20}$ a cloth simulation used in the short Geri's Game (1997), and Pixar's FizT dynamic hair and cloth animation software, which was used in Monster's Inc..

When a new nonlinear animation technology is on display in a Pixar feature, the film is accompanied by a media campaign that promotes the new technology through press pieces, DVD extras, and promotional videos. For example, a piece on the tech website CNET about Finding Dory (2016) talks about the technology Pixar developed to animate the elasticyet-soft properties of an octopus and also their new "auto-swim" software for procedurally animating fish. ${ }^{21}$ This rhetoric of innovation is echoed over and over in promotional material. For example a video produced by Pixar for Monster's Inc. resembles a sort of infomercial, with a cast of famous voice actors like Billy Crystal and James Coburn praising how revolutionary Pixar's FizT fur and cloth simulation software was at that time. ${ }^{22}$ A popular trope of this kind of promotion is to compare the challenges of the last feature project to the one currently being promoted. In a website article for Finding Nemo, supervising technical director Oren Jacob is quoted as saying "This film is far more complicated than 'Monsters, 
Inc.' in that almost every shot involves some kind of simulation program or simulated movement." 23

Depictions of these nonlinear animation tools also gesture toward their role in production labor as well. They highlight their new technology's ability to do animation work instead of animators. For example, an uncredited worker in Pixar's promotional piece for FizT explains that animating every single hair on a furry creature would be impossible, "all our animators would quit." The solution was to remove this task and displace it onto a new technology so, in his words, “our animators don't have to worry about it at all." 24 An article in Wired on FizT that coincided with the release of Monster's Inc. offers a rather idiosyncratic take on this logic. The author argues that while films with spectacular computer graphics have a tendency to suffer in terms of story, the way these technologies save animator labor allows them to focus on nuanced characters and story instead. ${ }^{25}$ This discourse resembles the logic of some of the representations of early industrial animation. Just as Walt Disney Productions represented the work of inkers and inbetweeners as allowing animators and managers to focus on creative work, nonlinear animation tools seem to provide a way of minimizing and compartmentalizing repetitive work. Much like registration pegs or rotoscoping, nonlinear simulation technologies are management tools.

With both the cases of Walt Disney Productions and Pixar, this emphasis on enabling creativity puts a very positive face on management tools that make for a more compliant and productive workforce. Nonlinearity puts a different frame on management than these early industrial techniques though. If Bray, Fleischer, and Walt Disney studios depicted industrial management as enabling creativity because it enabled direct and linear control, Pixar sees management enabling creativity because it occasions the unpredictable as well as flexible, responsive control. Fostering the unpredictable and shaping the results works just as well for simulations of monster fur as it does for a workforce, in Pixar's vision. This approach positions creativity and control so close as to be indistinguishable.

\section{Management Science}

Pixar's application of nonlinear animation to management did not happen in a vacuum. Management science is one of the many fields where nonlinear simulation has been employed as a tool. The jump from animation software to management theory is not as great as it might seem because 
nonlinear simulation is applied to all manner of complex, unpredictable phenomena. It has become an important part of many engineering and research disciplines, including aerospace, geology, climate science and meteorology, economics and finance, and social science. In many cases the development of tools for these disciplines has come to constitute its own field in computer science. While simulation techniques for animation are shared at the computer science special interest group ACM SIGGRAPH, management science simulation technology is shared at the Simulation and Modeling group (SIGSIM) or the Management Information Systems group (SIG MIS).

While management science follows the tradition of Taylor in that it theorizes management, management science and scientific management are two discrete concepts with important historical and conceptual differences. While scientific management studied particular industrial cases so that their efficiency and productivity might be improved, management science studies the organizational nature of systems themselves. Management science, in other words, seeks to uncover fundamental principles of systems in order that they can be applied as organizational techniques. As historian of management thought Morgen Witzel writes, "Scientific management was about exploring new methods; management science was and still is engaged in the quest for systems." ${ }^{26}$ This implies a different way of seeing the world, a different epistemology, an epistemology that is entwined with computer science and nonlinear simulation.

When it emerged management science was covalent with concepts like Norbert Wiener's cybernetics and Ludwig von Bertalanffy's general systems theory. ${ }^{27}$ The key early text of management science, Stanford Beer's Cybernetics and Management, first published in 1959, demonstrates this very clearly. ${ }^{28}$ Early cybernetics and systems theory were generally focused on self-regulating systems. In other words, they sought to understand how systems stayed stable through self-correction, as the name, from the Greek cybernétés or steersman, indicates. ${ }^{29}$ Computers, of course, provide an important conceptual model and tool for modeling such systems.

Very quickly though the paradigm of homeostasis began to be replaced with a greater interest in the way a given system interacts complexly and dynamically with other systems. Simulation tools were an important part in this turn. Even the very earliest computer simulations provided an opportunity to factor in for unexpected and random events. For example, the first computer simulation, the Monte Carlo Method, was a stochastic simulation. The Encyclopaedia of Operations Research and Management 
Science offers the following example of how simulations such as these are used in complex management science scenarios. Say a small company signs a new supply contract and they want to be prepared to fulfill it. They can simulate the stages of manufacture using discrete-event simulation and simulate the orders coming in at random intervals, thus testing their preparedness for an unpredictable number of orders. ${ }^{30}$ Nonlinear simulation is thus a powerful tool for testing management systems against the unpredictability of reality.

The key text that summarized the use of these techniques for management science was Jay Wright Forrester's 1961 book Industrial Dynamics. During the 1970s these ideas evolved even further, from asking how an organization could maintain stability in the face of uncertainty to asking how organizations themselves change. The concept of resilience originated in a 1973 paper by Canadian ecologist C. S. Holling, titled "Resilience and Stability of Ecological Systems." At its most simple, Holling's contribution was to ask why we assume the natural world is in a state of equilibrium when it is clearly not. The concept of organizational resilience extends from this because it asks how systems persist despite the fact of constant change. Holling writes that resilience, "is a measure of the persistence of systems and of their ability to absorb change and disturbance and still maintain the same relationships between populations or state variables. ${ }^{31}$ "While randomness, dynamics and unpredictability had been used to understand and manage systems for some time, Holling's study of ecological resilience was a new way of thinking that did not abhor change but instead embraced it as a necessary component of preserving a system. Resilience joined various other popular concepts in the 1970s such as chaos theory, catastrophe theory, and fractals that made unpredictable nonlinearity central and even desirable.

Nonlinear simulation has continued to play an important role in management science since. The contemporary management discipline of business process management (BPM) makes extensive use of nonlinear computer modeling. ${ }^{32}$ A subfield of study focused on the management of "creativity-intensive-processes" has also emerged, and it too is informed by these principles. ${ }^{33}$ The combination of computational tools and an epistemology of nonlinear systems have led to forms of management that are more flexible and responsive, more at home with uncertainty and contingency. If Taylor was focused on increasing output on a regulated, standardized, repetitive, linear production line, these techniques are more focused on processes with uncertain outcomes and on flexible, responsive 
forms of management. As the following section will discuss, Pixar's representations of their management theory show the influence of some of these more recent management science discourses, although Pixar puts their own inflection on management because their approach is also informed by their nonlinear animation tools and with their connection to the history of animation. They approach workers like a simulation of splashing water or flowing hair. This approach offers a more harmonious vision of management that minimizes dissent, offering a sanitized, technologized vision of creativity.

\section{Management Theory at Pixar}

Pixar promotes its management theory every bit as vociferously as it does its latest nonlinear animation technology. Representations of management can be found in DVD extras and public relations pieces in the press, just like their representations of new animation technology. A few company executives have also published articles and books that discuss the studio's approach to management. The most famous of these is of course former Pixar CEO (and soon to retire head of Disney Animation Studios) Ed Catmull's book Creativity Inc..

Pixar emerged amid a discourse of a post-industrial information society that privileges cognitive and symbolic labor and a discourse of technological disruptive innovation. One of the dominant paradigms of post-Fordist management focuses on the idea of workers as independent, self-managed, and self-promoting contractors. ${ }^{34}$ In the case of technology industries this takes the shape of entrepreneurship and disruption, as promoted by management theorist Clayton Christensen's book The Innovator's Dilemma and by the resurrection of Joseph Schumpeter's theory of creative destruction, which pits the heroic entrepreneur against the entrenched power of bureaucratic "giant concerns." 35 The discourses of self-management, worker autonomy, and entrepreneurialism are certainly present in Pixar's representations of itself. Its identity as the studio that brought "Silicon Valley bravado" to Hollywood and disrupted entrenched powerful studios is a classic of heroic Schumpeterian entrepreneurship. ${ }^{36}$ Yet Pixar's identity and its approach to management are more complex than this context would suggest.

Pixar's representation of its management theory fits delicately into its greater corporate image. On one hand, Pixar seeks to style itself in the tradition of industrial animation studios, especially Walt Disney 
Productions. ${ }^{37}$ The Incredibles featured a cameo from the two living members of Disney's "nine old men," Ollie Johnston and Frank Thomas, and in his book Ed Catmull notes the influence his childhood hero Walt Disney had on him. Catmull describes with admiration how Disney would acknowledge the importance of his forerunners like Winsor McCay and the Fleischer Brothers, suggesting Catmull himself does the same. ${ }^{38}$ On the other hand, as Malcolm Cook notes, Pixar has been a hardware and software company for a significant part of its history. ${ }^{39}$ As a company that was once owned by Steve Jobs, had an IPO two years before Amazon, and weathered the dot-com bubble like few other start-ups, it is one of the archetypal Silicon Valley tech companies (even if it is based in the East Bay). Pixar's approach to management straddles these identities of animation studio in the Fordist tradition and Silicon Valley tech company in many ways, and their use of nonlinear paradigms as a kind of animation frequently works to smooth over potential contradictions between the two.

The influence of a nonlinear epistemic paradigm is quite evident in Catmull's writing on management. He situates the company's relationship to the unforeseen and unpredictable as the core of their management theory. In Creativity Inc. he discusses people's innate fear of "random unforeseen events" and our tendency to look for patterns rather than randomness. ${ }^{40} \mathrm{He}$ contends that we should overcome this way of thinking and embrace the reality of randomness by designing organizations so that failure and the unexpected are not fatal threats. In Harvard Business Review he writes "we as executives have to resist our natural tendency to avoid or minimize risks." ${ }^{41}$ One can see the clear influence of management science and of the epistemology of nonlinear simulation in these statements. Rather than seeing "unforeseen random events" as something to resist and avoid, Catmull, like C. S. Holling, emphasizes how unpredictable complexity and randomness are central to any organization.

Further points Catmull makes seem to have been inspired directly by nonlinear animation technology. He writes, "to my mind randomness is not just inevitable; it is part of the beauty of life... The unpredictable is the ground on which creativity occurs." 42 The language he uses here puts one in mind of a water simulation, or the "genesis sequence" from Star Trek II. Animations such as these revel in the natural beauty of randomness and complexity, just as Catmull does in this quote. Indeed, Catmull makes this connection quite explicit. He writes that his insights about randomness and the unforeseen are attributable to his background in mathematics and physics. ${ }^{43}$ Catmull is clearly influenced by the epistemology of nonlinear 
simulation. Some further examples demonstrate how this fits in with the rest of Pixar's image as both animation studio and tech company.

Pixar's techniques for fostering the unforeseen and the unpredictable focus on three interlinking strategies. All of these strategies are addressed in Catmull's book, but they can also be found in a diversity of promotional material produced by the studio. Much of this material represents these strategies with notable lock-step consistency, indicating how carefully the studio controls the representation of its management theory. First is what Catmull refers to as "protection," that is, giving workers space to develop their ideas, experiment, and fail. Second is the studio's identity as a nonhierarchical organization that invites input from all workers, which is modeled on the concept of "total quality management" (TQM). Third is the way the architecture of the studio's buildings is designed to foster unpredictable interactions between workers. Notably, these principles contradict many of the Taylorist and Fordist principles promoted by the likes of Fleischer, Bray, and Walt Disney Studios. All of these strategies promote the opposite of efficiency and direct top-down managerial control. Indeed, behind-the-scenes material about Pixar offers a sort of spectacle of superfluous labor. Scholars including Paul Flaig have described Creativity Inc. as a sort of manual for post-Fordism, in part for the way it promotes concepts like worker self-management. ${ }^{44}$ Yet there is more to Pixar's approach to management than the difference between industrial and post-industrial management. Looking at the influence of nonlinear management concepts and the studio's relationship to animation's industrial past helps nuance our understanding.

The first strategy, Pixar's principle of protection, refers to protecting ideas so that workers have a chance to explore their potential, even if they end up contributing nothing in the end. Catmull writes that experimental projects and new ideas are often sacrificed in the name of efficiency. This, he argues, leads to stasis and ossification in old established institutions like film studios. ${ }^{45}$ There needs to be room for experimentation, for play, in order for the unforeseen to emerge. The idea of protection is tied to the studio's origin myth. In promotional material many senior staff express a great deal of affection for the early days of Pixar when their offices were in Point Richmond because it was a period when the company explored every idea of how they could make money. ${ }^{46}$ There was room for experimentation and play, even if it was obviously fruitless. Promotional videos about Pixar's history feature figures such as Pete Docter, Andrew Stanton, 
and Dylan Brown reminiscing about racing scooters around the office and trying to lodge stuffed animals in the ceiling. ${ }^{47}$

While this childish play at Point Richmond pushes the definition of experimental work to the point of absurdity, it is still related to the idea of protection. The point is that workers have been given the space to experiment, to discover something unexpected. The irreverent and playful activities of Pixar workers are a particularly popular subject for behind-the-scenes footage of the studio for promotional materials and DVD extras. They can be seen sliding across the Emeryville Campus's slippery floors in their socked feet or riding down flights of stairs in cardboard boxes wearing Viking helmets, for example (Pixar, 2005). Pixar has collected several stories of worker playfulness in a series titled Pixar Studio Stories. These shorts are narrated by Pixar workers with accompanying limited two-dimensional animation, conveying a sense of childish playfulness. They first appeared at promotional videos and Blu-ray extras for the release of Toy Story 3 (2010) and the re-release of Toy Story (1995) and Toy Story 2 (1999) on Blu-ray, but Pixar has continued to make them since. One story describes the studio's annual Halloween costume contest, ${ }^{48}$ another the studio's annual battle-of-the bands called Pixarpalooza. ${ }^{49}$ These activities, the narrator stresses, are not the product of over-achieving human resources workers. They are organized by the workers.

Perhaps the most classic example of this is the myth of the "Love Lounge." Animator Andrew Gordon discovered an empty space through an air-conditioning duct behind his office and set about turning it into a little club house. As he relates in Pixar Studios Stories, he thought he would get in trouble when he was found out, but instead management embraced his idea. ${ }^{50}$ These images of workers goofing off recall Fleischer Studio's representations of their animators' mischievous and unruly hijinks. Both examples strive to imbue the often-monotonous process of creating animations with a sense of liveliness. Yet, as Flaig notes, this "whistle while you work" discourse is a classic of post-Fordist creative labor. Furthermore, stories like the one from Point Richmond are narratives of entrepreneurial beginnings, a trope that evokes autonomy and self-management. These two sides of protection might seem to cooperate quite well, but there are some contradictions here. While Fleischer Studios tended to emphasize their ability to paternalistically manage the liveliness of their animators, Pixar erases any semblance of hierarchy or control. This contradiction is managed by the paradigm of nonlinear simulation, which focuses on the studio's ability foster liveliness, to animate its production 
process, in other words. Like a nonlinear animation, they set parameters that create the conditions for the unexpected and their management embraces the change that follows.

Richard McCulloch notes that these sorts of behind-the-scenes extratextual communications style the studio brand as fun and playful, and thus condition the reception their films. ${ }^{51}$ Pixar's promotion of its theory of protection works in harmony with this playful corporate ethos. The way they create spaces for creativity to happen conveys that the studio is a fun and playful place, but it also conveys the studio's ability to extract ideas from their creative workers through a technologically advanced management theory that is styled along the same principles as their computational animation technology.

The second strategy, Pixar's supposedly anti-hierarchical management philosophy, serves a very similar function as the concept of protection, ameliorating their corporate image, communicating the effectiveness of their nonlinear organizational paradigm, and negotiating their hybrid identity as modern tech company and traditional animation studio. Pixar's organizational identity is grounded in the principle of total quality management (TQM). Developed by mathematician W. Edwards Deming during the post-war reconstruction of Japanese industry, TQM puts the responsibility of ensuring the quality of a product on all workers. ${ }^{52}$ This puts it at odds with the Taylorist emphasis on efficiency. The classic example of TQM manufacturing illustrates this point. Under the Taylorist paradigm the assembly line is supposed to never stop, because this has catastrophic consequences for output efficiency. TQM holds that any worker should be given the power and responsibility to stop the line if they see a problem. This is an early example of post-Fordism because it shifts the responsibility of management onto the worker. Catmull was an early adopter of TQM in the United States. He describes it as "making production a creative endeavour that engages workers." 53 TQM is not itself an example of the influence of nonlinear thinking. It emphasizes the uniformity and consistency of a product, abhorring the unpredictable. Yet in the hands of Pixar it both connects with animation's industrial past and becomes inflected with nonlinear epistemology. It becomes a way of embracing unpredictable change.

In his book on Pixar CFO Lawrence Levy argues that the strict hierarchies of Hollywood studios and even large tech companies like IBM make them change and risk averse because everyone is trying to protect their position. ${ }^{54}$ Any disruption endangers entrenched power. Undermining 
hierarchy therefore invites the unexpected. Consider how Fleischer Studios and Walt Disney Productions represented their labor organization. The majority of the workers were a linear means to an end. Directors, producers, and top-level animators were constructed as the sites of creativity and the workers merely followed their instructions. In the case of Fleischer Studios most of the workers below the animator were invisible, while Walt Disney Productions compartmentalized their "pretty girl" inkers and inbetweeners into their own buildings. These hierarchies served a discourse of creativity in their own way, but they are highly linear. Pixar's TQM approach, by contrast, is not represented as a linear process of workers completing tasks exactly as directed. Instead, they "empower" workers to have input on the final creative product. The film thus emerges from an unpredictable nonlinear process that includes many sources of input. Catmull writes in Harvard Business Review, "Creativity must be present at every level of every artistic and technical part of the organization. ... It's like an archaeological dig where you don't know what you're looking for or whether you will even find anything. The process is downright scary." 55 Like Walt Disney Productions, Pixar is quite keen to show off their approach to management and sew it into their definition of animation. For Walt Disney Productions, linear means of control allow Disney to style himself as the creative agent behind cartoons, even if he does none of the animating himself. With Pixar, their TQM styled approach to management demonstrates their vision for animation as creating conditions for unpredictable things to happen.

As with all of these examples, this talk of non-hierarchical organization likely does not reflect actual practices. There are, of course, labor divisions within Pixar. And it is not as though anyone can make a change without oversight. ${ }^{56}$ Indeed in other cases Pixar paradoxically promotes more hierarchical features of their company like the "brain trust," a panel of the most senior creative minds.

Pixar's third management strategy is workspace design, more precisely the design of their studio headquarters in Emeryville, California. The Emeryville campus and its single main building, the Steve Jobs building, are the most central feature of their corporate identity. ${ }^{57}$ The Emeryville campus was constructed following Pixar's second feature A Bug's Life (1998) and their 1995 IPO, which raised the considerable funds necessary for such a project. The central design principle of the campus is fostering random unpredictable events. In the early stages of planning the building several ideas were put forth. John Lasseter, a director with a background 
in Disney animation, wanted to have a different building for each production. ${ }^{58}$ By contrast the final design saw everyone in a single building, with technical staff on one side and animations staff on the other, and both forced to congregate in the center. ${ }^{59}$ At the center is a large atrium with a coffee bar and a large staircase connecting the first and second floors. The purpose behind this design is to cause interactions between workers from different departments. Indeed, an early design had only one set of bathrooms in the middle of the building, forcing maximal interaction. ${ }^{60}$

The story of the Steve Jobs building's design is rehearsed constantly in behind-the-scenes public relations studio tours, with titles such as "Behind the Scenes at Pixar,"61 and "A Rare Look Inside Pixar Studios." 62 All of these publicity pieces follow almost the exact same set of talking points. Pieces by The New York Times, The Guardian, and The Huffington Post all marvel at the playful work culture and the Love Lounge, and they all talk about the design of the building as a way to foster "chance meetings." 63 Much like Pixar's concept of protection and their anti-hierarchical TQM philosophy, these stories model Pixar's corporate ethos as both playful and dynamically innovative. The visual imagination of these interactions is homologous with some of the software Pixar founders themselves developed for animation, such particle systems or cellular automata: simulations where individual points moving along unpredictable paths interact with each other and give rise to unexpected shapes and movements. One can imagine a blueprint of the atrium with such a simulation overlaid, with all of the employees represented by dots moving in random direction as they collide and interact. The atrium is a designed set of parameters that occasions unpredictable nonlinear events, a sort of synthetic creativity, a creativity that emerges not from direct deterministic fulfilled orders and efficiency but from mistakes and collisions.

The Steve Jobs building is perhaps the best symbol of the hybrid logic of Pixar's representation of its management theory. On one hand there is something very unlike post-Fordism about the building's representation. While other similar industries like the visual effects industry hire workers on six-month contracts and subcontract out work to competitive bidders, Pixar emphasizes having a brick-and-mortar building where they retain and cultivate their workers. ${ }^{64}$ Indeed, their desire to retain workers became the subject of controversy when it was revealed they had secret agreements with other studios not to poach each other's workers. As Eric Herhuth points out, this desire to retain workers, even to the point of breaking labor laws, contradicts "California-style" neoliberalism. ${ }^{65}$ However, on the other 
hand, the Steve Jobs building is distinctly unlike Walt Disney Production's approach to dividing labor into different buildings, the way John Lasseter apparently originally wanted. The building reinforces the image of Pixar as a non-hierarchical fun factory. Thus, neither of these discourses is sufficient to explain Pixar's promotion of the building. In order to understand it, one needs to understand the logic of nonlinear simulation behind their management theory. The Steve Jobs building is like a simulation, it is a field, a set of parameters, within which unpredictable creativity takes place. Pixar builds a box for their workers to be independent in. All of these examples of protection, worker playtime, non-hierarchical structures, and the Steve Jobs building's design, are about creating conditions and manipulating parameters to occasion the unexpected and the unlooked-for. This discourse offers a harmonious, utopian, vision where there is no conflict between creative chaos and control.

\section{Animating Offices}

Vivian Sobchack, Paul Flaig, and Eric Herhuth have all noted the way Pixar films like WALL-E build a bridge between the past and the present, between an age of mechanical photochemical media and Fordist employment and an age of frictionless digital media and self-managed creative work. ${ }^{66}$ In Herhuth's words they "mitigate extremes and render transition more palatable." ${ }^{67}$ One could certainly interpret Pixar's representation of their management theory in this way, as a bridge between past and present, but it is first and foremost a bridge between the identity of an animation company and a technology company, between culture and technology. Pixar promotes a hybrid approach to management, in tune with both animation's industrial past and post-Fordist management principles. They do this by employing a computational logic that seems to have the ability to resolve any conflict, to maximize control, and respond to unforeseen change while also facilitating creativity and animating workers. They animate workers much the way their nonlinear software animates pixels. Far from being halfway between the present and the past, this approach to management has been disseminated by its proponents as a solution to the demands of cognitive capitalism and creative work.

Studios like Walt Disney Productions constructed animation as management. Through the studio's mobilization of regimented disciplined workers, they spared their creative minds the labor of physically doing the animation, enabling them to direct the process. Their promotional 
material uses this above-and-below-the-line division to reassure the audience that even though hundreds of people worked on a cartoon, it was the product of a few creative minds. Their work as animators was directing the work of others. Pixar, by contrast, constructs management as animation. Through the vital animating force of nonlinear contingency Pixar constructs its vision of management as enlivening work by introducing unpredictability. This is a different way of conceiving of control, one where the job of the studio is not to control the liveliness of workers, but to enliven them.

Given Pixar's now mythic status as a successful Bay Area tech company once owned by Steve Jobs, and given the success of Ed Catmull's essays in the Harvard Business Review and his book Creativity Inc., this conception of management as nonlinear animation has spread to varied businesses that seek post-Fordist goals of creativity and innovation. True, concepts like open-plan offices and designing for creativity have been around at least since advertising company Chiat/Day opened their radical new offices in 1994, which Wired describes as being motivated by "egalitarian utopianism." ${ }^{\prime 68}$ But as Nerf guns and pet dogs proliferate in urban office spaces, it is difficult not to see the logic of nonlinear animation at work, enlivening workspaces and setting the conditions for unpredictability. The history of animation and of nonlinear simulation has had a greater influence on contemporary work life than one might assume.

Pixar's approach to management offers a recent chapter in the egalitarian utopianism of both office spaces and technology. Their seamless harmonious image of managing creativity recalls some of the more utopian visions of Californian techno-neoliberalism. Richard Barbrook and Andrew Cameron's essay on the "Californian ideology" was one of the first to note how an "emancipatory faith" in new technologies is linked to a "libertarian form of politics" that elides real world inequities. ${ }^{69}$ This use of emerging technologies to erase politics is also at work in the discourse of digital media platforms, which present themselves as "neutral" and "egalitarian," hiding the way they exercise algorithmic control and the political consequences that they entail. ${ }^{70}$ As recent work by Cathy O'Neil and Safiya Noble demonstrates, algorithms are far from being politically neutral. ${ }^{71}$ Instead, the logic of algorithmic control can act as a veneer of objective neutrality that makes bias seem impossible and irrelevant. But of course, as recent events have made clear, Pixar is not a harmonious utopia for everyone. News came out in 2017 about Lasseter's pattern of sexual harassment. ${ }^{72}$ Furthermore in 2018 former Pixar graphic designer 
Cassandra Smolcic criticized the pervasive sexism baked into Pixar culture, offering a variety of examples based on her five years working there. ${ }^{73}$ Interestingly, in Lasseter's vaguely contrite memo to the workers of Pixar that responds to accusations of sexual harassment he frames his behavior as a failure in managing creativity. He writes, "This kind of creative culture takes constant vigilance to maintain. It's built on trust and respect, and it becomes fragile if any members of the team don't feel valued." "' Even when issues of justice and equality emerge, Pixar's approach to management feels sanitized of history, politics, and difference. Instead, it is all about creating conditions and parameters.

A version of this chapter appeared as an article in Animation: An Interdisciplinary Journal.

Jordan Gowanlock, "Animating Management: Nonlinear Simulation and Management Theory at Pixar," Animation (15:1) pp. 61-76. Copyright@2020.DOI:https://doi.org/10.1177/1746847719898783.

\section{Notes}

1. Donald Crafton, Before Mickey: The Animated Film, 1898-1928 (Chicago: University of Chicago Press, 1993).

2. Nicholas Sammond, Birth of an Industry: Blackface Minstrelsy and the Rise of American Animation (Durham: Duke University Press, 2015), 91-92.

3. Siegfried Zielinski, "Expanded Animation: A Small Genealogy of the Idea and Praxis That Breathe a Soul into Dead Things," in Pervasive Animation, ed. Suzanne Buchan, AFI Film Readers (New York: Routledge, Taylor \& Francis Group, 2013), 26.

4. Tarleton Gillespie, "The Politics of 'Platforms," New Media \& Society 12, no. 3 (May 1, 2010): 347-64; Cathy O'Neil, Weapons of Math Destruction: How Big Data Increases Inequality and Threatens Democracy (New York: Crown, 2016); Safiya Umoja Noble, Algorithms of Oppression: How Search Engines Reinforce Racism (New York: NYU Press, 2018).

5. Lawrence Levy, To Pixar and Beyond (Boston: Houghton Mifflin Harcourt, 2017), 170.

6. Paul Flaig, "Slapstick after Fordism: WALL-E, Automatism and Pixar's Fun Factory," Animation 11, no. 1 (March 1, 2016): 61.

7. Flaig, "Slapstick After Fordism," 61; Chris Bilton, Management and Creativity: From Creative Industries to Creative Management (Malden, Mass: Blackwell, 2010), 81-87.

8. Scott Bukatman, The Poetics of Slumberland: Animated Spirits and the Animating Spirit (Berkeley: University of California Press, 2012), 16-19. 
9. Morgen Witzel, A History of Management Thought (London: Routledge, 2017), 110-13.

10. Witzel, A History of Management Thought, 113.

11. Sammond, Birth of an Industry, 94.

12. Crafton, Before Mickey, 163-67.

13. Sammond, Birth of an Industry, 91.

14. Sammond, Birth of an Industry, 92.

15. Sammond studies these tropes of mischievousness and struggle against control in the context of racialized representations and the role of minstrelsy in early American animation.

16. Sammond, Birth of an Industry, 110 .

17. As Sammond puts it, Walt Disney “...like an industrial Shiva, multiplied his hands manifold times, the godlike manager of a Fordist animation factory." Sammond, Birth of an Industry, 27.

18. Alain Fournier and Loren Carpenter, "Computer Rendering of Stochastic Models," Communications of the ACM 25, no. 6 (1982): 371-84.

19. William T Reeves, "Particle Systems—a Technique for Modeling a Class of Fuzzy," Proceedings of the 10th Annual Conference OnComputer Graphics and Interactive Techniques, 1983, 371-75.

20. Michael Kass and Gavin Miller, "Rapid, Stable Fluid Dynamics for Computer Graphics," ACM Computer Graphics 24, no. 4 (1990): 49-57.

21. Brian Tong, Inside Pixar: The Tech behind "Finding Dory" (CNET, 2016), https://www.youtube.com/watch?v=cGUJokMlGUU

22. Pixar Animation Studios, Animating Fur, 2001, https://video.disney. $\mathrm{com} /$ watch/animating-fur-4bb39e41480d5a8833003bl 5

23. Vicki Arkoff, "Ultimate Guide to 'Finding Nemo," HowStuffWorks, November 7, 2006, https://lifestyle.howstuffworks.com/family/activities/how-finding-nemo-works.htm

24. Pixar Animation Studios, Animating Fur.

25. Robin Clewley, "Monsters, Inc. Used Monster Tools," Wired, November 2, 2001, https://www.wired.com/2001/11/monsters-inc-used-monstertools/

26. Witzel, A History of Management Thought, 180.

27. Norbert Wiener, Cybernetics; or, Control and Communication in the Animal and the Machine (Cambridge: MIT Press, 2019); Ludwig von Bertalanffy, General System Theory: Foundations, Development, Applications (New York: Braziller, 2015).

28. Stanford Beer, Cybernetics and Management (London: English University Press, 1987).

29. Reinhold Martin, The Organizational Complex: Architecture, Media, and Corporate Space (Cambridge, Mass.; London: The MIT Press, 2005), 19. 
30. Saul Gass and Michael C Fu, Encyclopaedia of Operations Research and Management Science (Boston: Springer, 2013), 626.

31. C.S. Holling, "Resilience and Stability of Ecological Systems," Annual Review of Ecology and Systematics 4, no. 1 (1973): 14.

32. Witzel, A History of Management Thought, 181.

33. Stefan Seidel, "Toward a Theory of Managing Creativity-Intensive Processes: A Creative Industries Study," Information Systems and E-Business Management 9, no. 4 (December 1, 2011): 407-46, https://doi. org/10.1007/s10257-009-0123-7

34. Bilton, Management and Creativity, 81-87.

35. Jospeph Schumpeter, Capitalism, Socialism and Democracy (London: Routledge, 2003); Thomas K McCraw, Prophet of Innovation: Joseph Schumpeter and Creative Destruction (Cambridge: Harvard University Press, 2010).

36. Levy, To Pixar and Beyond, 2017, 170.

37. Eric Herhuth notes that Pixar has both rebelled against Disney at times, while also "perpetuating its tenets." Eric Herhuth, Pixar and the Aesthetic Imagination: Animation, Storytelling, and Digital Culture (Oakland: University of California Press, 2016), 6.

38. Edwin Catmull and Amy Wallace, Creativity, Inc.: Overcoming the Unseen Forces That Stand in the Way of True Inspiration (Random House, 2014), 17-18.

39. Malcolm Cook, "Pixar, 'The Road to Point Reyes' and the Long History of Landscape in New Visual Technologies," in Animated Landscapes: History, Form, and Function, ed. Chris Pallant (London: Bloomsbury Academic, 2015), 65, https://eprints.soton.ac.uk/385604/

40. Catmull and Wallace, Creativity, Inc., 2014, 139-45.

41. Ed Catmull, "How Pixar Fosters Collective Creativity," Harvard Business Review, September 1, 2008, https://hbr.org/2008/09/how-pixarfosters-collective-creativity

42. Catmull and Wallace, Creativity, Inc., 2014, 139.

43. Catmull and Wallace, Creativity, Inc., 148.

44. Flaig, "Slapstick after Fordism," 71.

45. Catmull and Wallace, Creativity, Inc., 2014, 123-30.

46. In his book on Pixar Lawrence Levy describes this period of unprofitability less favorably, describing it more as a period where they did not know how to make money. Levy, To Pixar and Beyond, 26-92.

47. John Lasseter, Toy Story 2 Blu-Ray Extras, Blu-ray (Pixar Animation Studios, 2010).

48. Disney Pixar, Pixar Studio Stories: Halloween, 2018, https://www.youtube.com/watch?v=ii6OWdomgl0 
49. Disney Pixar, Pixar Studio Stories: Pixarpalooza, 2019, https://www.youtube.com/watch?v=z6cWuMR9rCg

50. The short describes all of the dignitaries who were invited into the lounge while eliding the fact that it was actually replaced with a more officially sanctioned secret lounge "The Lucky 7 Club."

51. R McCulloch, "Whistle While You Work: Branding, Critical Reception and Pixar's Production Culture," in Storytelling in the Media Convergence Age: Exploring Screen Narratives, ed. R Pearson and A.N. Smith (Basingstoke: Palgrave Macmillan, 2015), 174-89.

52. A full account of Deming's theory including his fourteen points for management can be found in his book Out of the Crisis (1986).

53. Catmull and Wallace, Creativity, Inc., 2014, 50-55.

54. Levy, To Pixar and Beyond, 2017, 84.

55. Catmull, "How Pixar Fosters Collective Creativity," September 1, 2008.

56. Catmull in fact qualifies his claims at one point, saying that they apply to input and communications rather than chain of commands. Catmull and Wallace, Creativity, Inc., 66.

57. McCulloch, "Whistle While You Work: Branding, Critical Reception and Pixar's Production Culture," 175.

58. Isaacson, Steve Jobs, 430.

59. Pixar has expanded since building the Steve Jobs building, including a second building on the Emeryville campus, called the Brooklyn building, and a building in Vancouver, British Columbia, which was later closed.

60. Although different accounts attribute this idea to different people, there is broad agreement that the highly impractical and uncompromising idea of having only one set of bathrooms at the center of the gigantic facility was Steve Jobs'. Catmull and Wallace, Creativity, Inc., 264.

61. Paul MacInnes, Behind the Scenes at Pixar (The Gaurdian, 2010), https:// www.youtube.com/watch? v=fytHjRvkn-U

62. Jeremy Beiler and Melena Ryzik, A Rare Look Inside Pixar Studios (The New York Times, 2011), https://carpetbagger.blogs.nytimes. com/2011/02/10/video-a-rare-look-inside-pixar-studios/. There is no studio tour of the Emeryville campus, although workers are allowed to give their own tours to acquaintances. Thus, there is no official studio tour text to read beyond PR tours published in the press.

63. Julee Morrison, "An Inside Look at Pixar Animation Studios," Huffington Post, April 19, 2016, https://www.huffingtonpost.com/julee-morrison/ an-inside-look-at-pixar-a_b_9670088.html

64. Bill Taylor, "Pixar's Blockbuster Secrets," Harvard Business Review, July 8, 2008, https://hbr.org/2008/07/pixars-blockbuster-secrets; Catmull and Wallace, Creativity, Inc., 2014, 79.

65. Herhuth, Pixar and the Aesthetic Imagination, 3-4. 
66. Sobchack, "Animation and Automation, or, the Incredible Effortfulness of Being"; Flaig, "Slapstick after Fordism"; Herhuth, Pixar and the Aesthetic Imagination.

67. Herhuth, Pixar and the Aesthetic Imagination, 5.

68. Warren Berger, "Lost in Space," Wired, February 1, 1999, https://www. wired.com/1999/02/chiat-3/

69. Barbrook and Cameron, "The Californian Ideology."

70. Gillespie, "The Politics of 'Platforms."

71. O'Neil, Weapons of Math Destruction; Noble, Algorithms of Oppression.

72. Kim Masters, "John Lasseter Taking Leave of Absence From Pixar Amid 'Missteps," The Hollywood Reporter, 2017, https://www.hollywoodreporter.com/news/john-lasseter-taking-leave-absence-pixar-missteps1057113

73. Cassandra Smolcic, "Pixar's Sexist Boys Club," Medium Be Yourself, June 2018, https://byrslf.co/pixars-sexist-boys-club-9d621567fdc9

74. Masters, "John Lasseter Taking Leave of Absence from Pixar Amid 'Missteps.'”

Open Access This chapter is licensed under the terms of the Creative Commons Attribution 4.0 International License (http://creativecommons.org/licenses/ by $/ 4.0 /$ ), which permits use, sharing, adaptation, distribution and reproduction in any medium or format, as long as you give appropriate credit to the original author(s) and the source, provide a link to the Creative Commons license and indicate if changes were made.

The images or other third party material in this chapter are included in the chapter's Creative Commons licence, unless indicated otherwise in a credit line to the material. If material is not included in the chapter's Creative Commons licence and your intended use is not permitted by statutory regulation or exceeds the permitted use, you will need to obtain permission directly from the copyright holder.

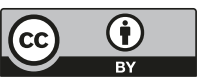

